\title{
What determines the sign of the evapotranspiration response to afforestation in European summer?
}

\author{
Marcus Breil $^{1}$, Edouard L. Davin ${ }^{2}$, and Diana Rechid ${ }^{3}$ \\ ${ }^{1}$ Institute for Meteorology and Climate Research, Karlsruhe Institute of Technology, Karlsruhe, Germany \\ ${ }^{2}$ Department of Environmental Systems Science, ETH Zurich, Zurich, Switzerland \\ ${ }^{3}$ Climate Service Center Germany, Helmholtz-Zentrum Geesthacht, Hamburg, Germany
}

Correspondence: Marcus Breil (marcus.breil@kit.edu)

Received: 16 July 2020 - Discussion started: 14 August 2020

Revised: 14 December 2020 - Accepted: 18 January 2021 - Published: 3 March 2021

\begin{abstract}
Uncertainties in the evapotranspiration response to afforestation constitute a major source of disagreement between model-based studies of the potential climate benefits of forests. Forests typically have higher evapotranspiration rates than grasslands in the tropics, but whether this is also the case in the midlatitudes is still debated. To explore this question and the underlying physical processes behind these varying evapotranspiration rates of forests and grasslands in more detail, a regional model study with idealized afforestation scenarios was performed for Europe. In the first experiment, Europe was maximally forested, and in the second one, all forests were turned into grassland.

The results of this modeling study exhibit the same contradicting evapotranspiration characteristics of forests and grasslands as documented in observational studies, but by means of an additional sensitivity simulation in which the surface roughness of the forest was reduced to grassland, the mechanisms behind these varying evapotranspiration rates could be revealed. Due to the higher surface roughness of a forest, solar radiation is more efficiently transformed into turbulent sensible heat fluxes, leading to lower surface temperatures (top of vegetation) than in grassland. The saturation deficit between the vegetation and the atmosphere, which depends on the surface temperature, is consequently reduced over forests. This reduced saturation deficit counteracts the transpiration-facilitating characteristics of a forest (deeper roots, a higher leaf area index, LAI, and lower albedo values than grassland). If the impact of the reduced saturation deficit exceeds the effects of the transpiration-facilitating characteristics of a forest, evapotranspiration is reduced compared to grassland. If not, evapotranspiration rates of forests are
\end{abstract}

higher. The interplay of these two counteracting factors depends on the latitude and the prevailing forest type in a region.

\section{Introduction}

Afforestation is frequently discussed as a potential strategy to mitigate the effects of human-induced climate change (e.g., Sonntag et al., 2016; Harper et al., 2018; Roe et al., 2019; Davin et al., 2020). One benefit of afforestation is that forests are generally able to take up more $\mathrm{CO}_{2}$ than grasslands (IPCC, 2019). Another advantage is that forests can have a cooling effect on the land surface due to increased evapotranspiration rates compared to grasslands (e.g., Bonan, 2008; Bright et al., 2017; Duveiller et al., 2018). According to our present knowledge about the biogeophysical effects of forests and grasslands, this increased forest evapotranspiration is caused by deeper roots (Schenk and Jackson, 2003) and a higher leaf area index (LAI; e.g., HendersonSellers, 1993) than in grassland, whose influence can be attenuated by the reduced photosynthetic activity of forests and an associated stomata closure (Leuzinger et al., 2005). The evaporative cooling effect is particularly pronounced in the tropics (Von Randow et al., 2004) but is unclear at midlatitudes (Bonan, 2008). While several observation-based studies show the higher evapotranspiration rates of forests at midlatitudes (e.g., Zhang et al., 2001; Li et al., 2015; Chen et al., 2018; Duveiller et al., 2018), some studies exhibit an opposite behavior of forests with reduced evapotranspiration rates compared to grasslands (e.g., Wicke and Bernhofer, 1996; 
Teuling et al., 2010; Williams et al., 2012). The actual evapotranspiration rates of forests and grasslands are therefore subjects of controversial discussions within the scientific community (e.g., Teuling, 2018).

An adequate methodology to improve the understanding about this contradicting evapotranspiration responses is the application of model simulations in which factorial experiments are performed in order to disentangle the role of different processes. Also within executed model intercomparison studies, a number of models simulate increased evapotranspiration, and some models simulate decreased evapotranspiration in forests during summer (de Noblet-Ducoudré et al., 2012; Lejeune et al., 2017; Davin et al., 2020). The mechanisms behind the diverging evapotranspirative behavior of forests and grasslands in the midlatitudes are consequently still an unsolved issue. Thus, to be able to correctly assess the suitability of afforestation as an effective mitigation strategy in the midlatitudes, the understanding of the biogeophysical processes in forests and grasslands needs to be improved. Only if the evapotranspirative behavior of forests and grasslands can be properly explained can the impact of these land use types on the near surface climate conditions be evaluated.

In this study, therefore, the question of how afforestation can lead in some parts of the midlatitudes to increased evapotranspiration rates in summer and in some regions to a reduction will be further explored. For this, idealized and extensive afforestation scenarios are applied in regional climate simulations for Europe. This approach allows for an isolated view on the biogeophysical processes in forest and grasslands on a large scale which is not provided by selective point observations. The theoretical background of the transpiration flux calculation and the simulation setup of the afforestation experiments is provided in Sect. 2. Based on the presented simulation results in Sect. 3, a mechanism explaining the varying evapotranspiration rates of forest and grasslands is discussed in Sect. 4.

\section{Method}

To investigate the processes determining the sign of the evapotranspiration response to afforestation in the midlatitudes, simulations with the regional climate model COSMO-CLM (Rockel et al., 2008) coupled with the land surface model (LSM) VEG3D (Breil and Schädler, 2017) are performed for Europe. Since afforestation is primarily affecting the transpiration characteristics of a land surface, it is assumed that changes in total evapotranspiration in summer are mainly caused by changes in the transpiration rates as indicated by, e.g., Meier et al. (2018). The focus of the paper will therefore be on the impact of afforestation on transpiration changes, and we try to explain evapotranspiration responses by changes in the transpiration characteristics. According to this, in a first step, the theoretical background of transpiration is presented, and its implementation in the LSM VEG3D is discussed in detail. Subsequently, the setup of the performed simulations is described.

\subsection{Theoretical background}

Transpiration can be described as a water flux from a vegetated land surface into the atmosphere. This flux is determined by two factors: (1) the saturation deficit between the vegetation and the atmosphere $q_{\mathrm{s}}\left(T_{\mathrm{scf}}\right)-q_{\mathrm{a}}$ and (2) a transfer coefficient $c$.

$Q=p \times c\left(q_{\mathrm{s}}\left(T_{\mathrm{scf}}\right)-q_{\mathrm{a}}\right)$,

where $q_{\mathrm{s}}\left(T_{\mathrm{scf}}\right)$ depends on the surface temperature $T_{\mathrm{scf}}$ and is derived from the Magnus equation. The surface temperature is in this case the temperature at the top of the vegetation, and $p$ is the air density. In state of the art LSMs, the transfer coefficient $c$ is generally regarded as a resistance that has to be overcome by the transpiration flux (e.g., Niu et al. 2011; Oleson et al., 2013). In VEG3D, the LSM applied in this study, this drag coefficient is described through two resistances in series (Deardorff, 1978 and Taconet et al., 1986): an atmospheric resistance $r_{\mathrm{a}}$ and a canopy resistance $r_{\mathrm{c}}$.

$c=\frac{\text { frac }_{\mathrm{dry}}}{r_{\mathrm{c}}+r_{\mathrm{a}}}$,

where frac $\mathrm{dry}_{\mathrm{r}}$ represents the fraction of dry leaf surface.

In $r_{\mathrm{a}}$, the turbulent atmospheric conditions for the transfer of water vapor are included, which are calculated by means of an empirical parameter $C_{\text {leaf }}$ and the friction velocity $u_{*}$.

$r_{\mathrm{a}}=\frac{C_{\text {leaf }}}{u_{*}}$,

where $C_{\text {leaf }}$ describes an empirical interrelation between the turbulent exchange and the leaf area index (LAI; Taconet et al., 1986) in relation to the leaf geometry, represented by the plant-specific parameter $c_{\mathrm{veg}}$ (Goudriaan, 1977).

$C_{\text {leaf }}=\frac{1+0.5 \times \mathrm{LAI}}{0.04 \times \mathrm{LAI} \times c_{\mathrm{veg}}}$,

where $u_{*}$ is classically derived from the Monin-Obukhov similarity theory (Monin and Obukhov, 1954) and as such mainly dependent on $z_{0}$.

$u_{*}=\frac{k\left(v_{z_{\mathrm{a}}}-v_{z_{0}}\right)}{\ln \left(\frac{z_{\mathrm{a}}}{z_{0}}\right)+\Psi\left(\frac{z_{\mathrm{a}}}{L_{*}}\right)+\Psi\left(\frac{z_{0}}{L_{*}}\right)}$,

where $z_{\mathrm{a}}$ is the height of the lowest atmospheric model level, $z_{0}$ is the roughness length, $v_{z_{\mathrm{a}}}$ and $v_{z_{0}}$ are consequently the wind velocities at the respective heights, $k$ is the Karman constant, $L_{*}$ is the Monin-Obukhov length, and $\Psi$ is a stability function based on Businger et al. (1971) establishing empirical relationships in turbulent motion which depend on the atmospheric stratification. According to Eqs. (4) and (5), 
Table 1. The impact of the different influencing factors on transpiration of forests in comparison to grasslands.

\begin{tabular}{ll}
\hline Parameter & Impact on transpiration \\
\hline Leaf geometry & Facilitates transpiration \\
Surface roughness & Facilitates transpiration \\
LAI & Facilitates transpiration \\
Albedo & Facilitates transpiration \\
Root depth & Facilitates transpiration \\
Stomatal resistance & Facilitates transpiration \\
Saturation deficit & Attenuates transpiration \\
\hline
\end{tabular}

$r_{\mathrm{a}}$ is consequently affected by three vegetation parameters, namely a plant-specific parameter $c_{\mathrm{veg}}(a)$, the surface roughness $z_{0}(b)$ and the LAI $(c)$, but out of these three parameters, the influence of the surface roughness $(b)$ on $r_{\mathrm{a}}$ and thus on the transfer coefficient $c$ is clearly dominant (Goudriaan, 1977).

In $r_{\mathrm{c}}$, the plant physiological processes of transpiration are considered. Soil water is thereby extracted by the roots and transported into the leaves. There, the water is released through the stomata into the atmosphere. Plants are regulating this water flux by the closure of the stomata. In the case of high solar radiation, for instance, stomata can be opened to increase the evaporative cooling. On the other hand, in the case of limited water availability, the stomata can be closed, and transpiration is reduced. These different canopy functions are described by $r_{\mathrm{c}}$ (Deardorff, 1978 and Taconet et al., 1986):

$r_{\mathrm{c}}=r_{\min } \frac{1+0.5 \times \mathrm{LAI}}{\mathrm{LAI}}\left(\frac{S_{\max }}{S+0.03 \times S_{\max }}+\left(\frac{w_{\text {wilt }}}{w_{\text {root }}}\right)^{2}\right)$,

where $r_{\mathrm{c}}$ depends on the net shortwave radiation, whereby $S$ is the actual net shortwave radiation and $S_{\max }$ constitutes a seasonally varying maximum shortwave radiation. Vegetation affects these components by the albedo parameter $(d)$. In VEG3D, a bulk surface albedo with prescribed parameter values is used depending on the vegetation type. Additionally, $r_{\mathrm{c}}$ depends on the soil water availability, which is described by the relation of the wilting point $w_{\text {wilt }}$ to the soil water content within the rooted soil $w_{\text {root }}$. Vegetation affects the soil water content by the root depth parameter $(e)$. Furthermore, $r_{\mathrm{c}}$ is controlled by the LAI (c) and a plant-specific stomata coefficient $r_{\min }(f)$ representing plant-specific stomatal resistance characteristics (Deardorff, 1978).

Thus, in VEG3D, transpiration depends on six different vegetation parameters $(a-f)$ besides the humidity gradient (1) (Table 1). The values of these six vegetation parameters in VEG3D are in line with the parameter values used in other state of the art LSMs (Breil et at., 2020). In a forest, these vegetation characteristics are different to grassland.

Trees have generally larger leaves than grass. The leaf geometry parameter $c_{\text {veg }}$ is therefore higher for forests than for grasslands (Taconet et al., 1986). Thus, $r_{\mathrm{a}}$ is reduced and transpiration is facilitated.

The surface roughness of a forest is higher than of grassland (Garratt, 1993; Henderson-Sellers, 1993). The turbulent mixing is consequently increased, which in turn reduces $r_{\mathrm{a}}$ and facilitates transpiration.

The LAI for forests is higher than for grassland (e.g., Henderson-Sellers, 1993). With a high LAI, more water can be transpired. The canopy resistance $r_{\mathrm{c}}$ of forests is therefore reduced. Furthermore, a high LAI increases interception, which additionally increases evapotranspiration.

A forest is characterized by lower albedo values than grassland (Garratt, 1993; Henderson-Sellers, 1993). Thus, the net shortwave radiation $S$ is increased. This leads particularly in summer to a reduced canopy resistance $r_{\mathrm{c}}$ which facilitates transpiration.

The roots in a forest reach deeper than in grassland (Schenk and Jackson, 2003). During dry summer conditions, therefore, the available amount of water for transpiration is increased in a forest. The water stress for the trees is consequently low, leading again to a reduced $r_{\mathrm{c}}$.

Values of $r_{\min }$ for forest and grassland vary in literature but are on a similar level in VEG3D, as stated by Garratt (1993). In the presented study, a lower $r_{\text {min }}$ for forest is used than for grassland, leading to lower $r_{\mathrm{c}}$ values under the same boundary conditions.

Thus, each of the six factors $(a-f)$ which affect the transfer coefficient $c$ (Eq. 2) in the transpiration flux calculation (Eq. 1) in VEG3D is reduced in forest compared to grassland and thus facilitates transpiration during summer. According to Eq. (1), a reduced transpiration in a forest must consequently be connected to a reduced saturation deficit between the vegetation and the atmosphere. In the following, therefore, the impact of this saturation deficit on the transpiration fluxes of forests and grasslands and its relations to the vegetation parameters $(a-f)$ is investigated. For this, an idealized model study is conducted to explore the reasons for the uncertain effects of afforestation in European summer.

\subsection{Simulation setup}

As described in the previous section, transpiration depends on two factors: (1) the saturation deficit between the surface and the atmosphere and (2) the transfer coefficient $c$. The second factor can thereby be described by two resistances, $r_{\mathrm{a}}$ and $r_{\mathrm{c}}$, which are controlled by six vegetation parameters $(a-f)$. Now, the impact of all these components on the transpiration flux of forests and grasslands is investigated by performing idealized afforestation simulations with a regional climate model.

For this, two extreme land use change scenarios for Europe are simulated. In the first experiment, Europe is completely covered with forest where trees can realistically grow (FOREST); in the second experiment, all forest is turned into grassland (GRASS). By using this approach, the differences 


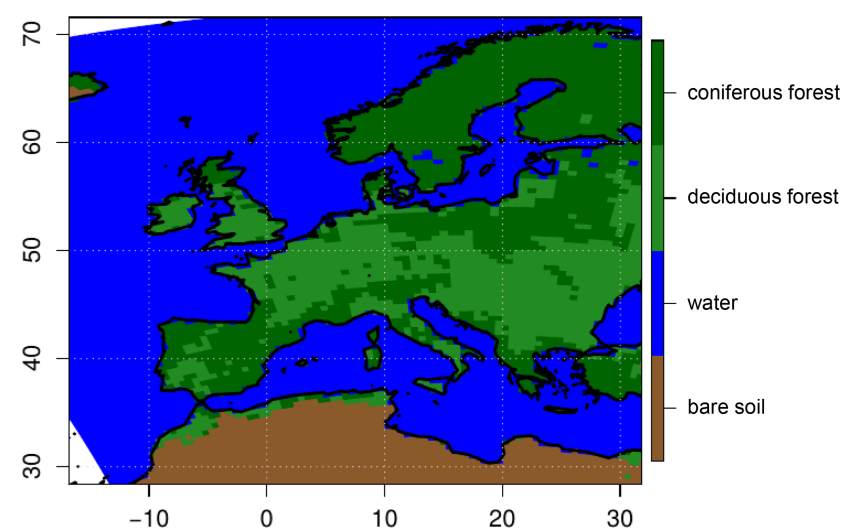

Figure 1. Spatial distribution of the land use classes used in the FOREST experiment.

in transpiration between forests and grasslands can be isolated and analyzed on a large scale which is not given in observation studies. In this way, the mechanisms leading to the different transpiration responses to afforestation in European summer can be explored in detail.

In FOREST, two different forest types are used (coniferous and deciduous); in GRASS, only one grassland class is applied. The spatial distribution of the two different forest types in FOREST is illustrated in Fig. 1. Coniferous and deciduous forest, as well as grassland, have different vegetation characteristics, leading to different transpiration rates, as already described in Sect. 2.1. The vegetation parameters used for each land use class are summarized in Table 2. The study is embedded in the LUCAS initiative (Rechid et at., 2017). The model domain is the Coordinated Downscaling Experiment - European Domain (EURO-CORDEX; Jacob et al., 2014) at a horizontal resolution of $0.44^{\circ}(\sim 50 \mathrm{~km})$. The simulations were driven by ERA-Interim reanalyses (Dee et al., 2011) at the lateral boundaries and at the lower boundary over sea. The simulation period is 1986-2015. A spin-up of 6 years was performed before 1986 .

To be able to better distinguish between the effects of $r_{\mathrm{a}}$ and $r_{\mathrm{c}}$ on the respective transpiration fluxes, an additional sensitivity run with the FOREST setup is performed (ROUGH). In this simulation, the surface roughness of forest is replaced by the surface roughness of grassland. All the other vegetation parameters of forest, like albedo or LAI, remained unchanged. Since the surface roughness affects only $r_{\mathrm{a}}$ and not $r_{\mathrm{c}}$, this sensitivity simulation gives the opportunity to draw conclusions about the impact of both resistances on the transpiration fluxes.

\section{Results}

\subsection{Evapotranspiration}

In southern and central Europe, evapotranspiration is reduced in the FOREST run compared to the GRASS simulation (Fig. 2a). The evapotranspiration reduction in FOREST is in this context particularly strong in southern Europe, but in northern Europe, the opposite is the case, and evapotranspiration is increased in FOREST. In central Europe, regions with reduced evapotranspiration rates in FOREST coincide with regions covered by deciduous forest (Fig. 1). This indicates that differences in evapotranspiration rates between forests and grassland are affected by the prevailing forest type in a region. Thus, the different vegetation characteristics $(a-f)$ of deciduous and coniferous forest must have an impact on the intensity of the evapotranspiration response to afforestation, but, since both forest types have lower resistance values (higher $c$ values) than grasslands, both forest types should also more strongly promote transpiration than grasslands, which seems to be in contradiction to the reduced evapotranspiration rates of deciduous forests in central Europe. Therefore, the resistance values of the different forest types cannot solely explain the opposing transpiration signals.

In general, differences in evapotranspiration rates are frequently connected to differences in the soil water contents and thus differences in the amount of available water for evapotranspiration, but due to their deeper roots, forests have access to a larger amount of available soil water than grasslands (Fig. 3a) so that the drought stress in summer is lower in the FOREST simulation than in the GRASS run. The reduced evapotranspiration rates in central and southern Europe in FOREST can consequently not be caused by lower soil water contents.

Furthermore, by means of differences in the soil water content, the contribution of transpiration and soil evaporation to total evapotranspiration can be indirectly assessed. Fig. 3b-d show the differences in soil water contents between the FOREST simulation and the GRASS run for different soil depths. Differences in the upper $5 \mathrm{~cm}$ of the soil (Fig. 3b) are used as an indicator for differences in the soil evaporation since this process is executed through the soil surface (although soil evaporation can also be affected by soil depths deeper than $5 \mathrm{~cm}$ ). At a depth of $15 \mathrm{~cm}$ (Fig. 3c), the maximum root density of grassland is located and at $75 \mathrm{~cm}$ depth (Fig. 3d) that of forests. Thus, differences in these soil depths refer to the contribution of transpiration to total evapotranspiration in each simulation. Just slight differences occur between the FOREST and the GRASS simulations for the upper soil (Fig. 3b). This is because the upper soil layers are in both simulations almost completely dry in summer. The contribution of soil evaporation to total evapotranspiration is therefore low in both simulations. This confirms the proposed assumption at the beginning of the study 
Table 2. Vegetation parameters of the different land use classes in summer.

\begin{tabular}{lrrrrrr}
\hline & Albedo & LAI & $r_{\text {min }}$ & $\begin{array}{r}\text { Root depth } \\
\text { (density }<2 \%)\end{array}$ & $z_{0}$ & $c_{\text {veg }}$ \\
\hline Coniferous forest & 0.11 & 9 & 120 & $1.0 \mathrm{~m}$ & $1.0 \mathrm{~m}$ & 1.75 \\
Deciduous forest & 0.15 & 8 & 120 & $2.0 \mathrm{~m}$ & $0.8 \mathrm{~m}$ & 2.1 \\
Grassland & 0.2 & 4 & 150 & $0.5 \mathrm{~m}$ & $0.03 \mathrm{~m}$ & 1.2 \\
\hline
\end{tabular}
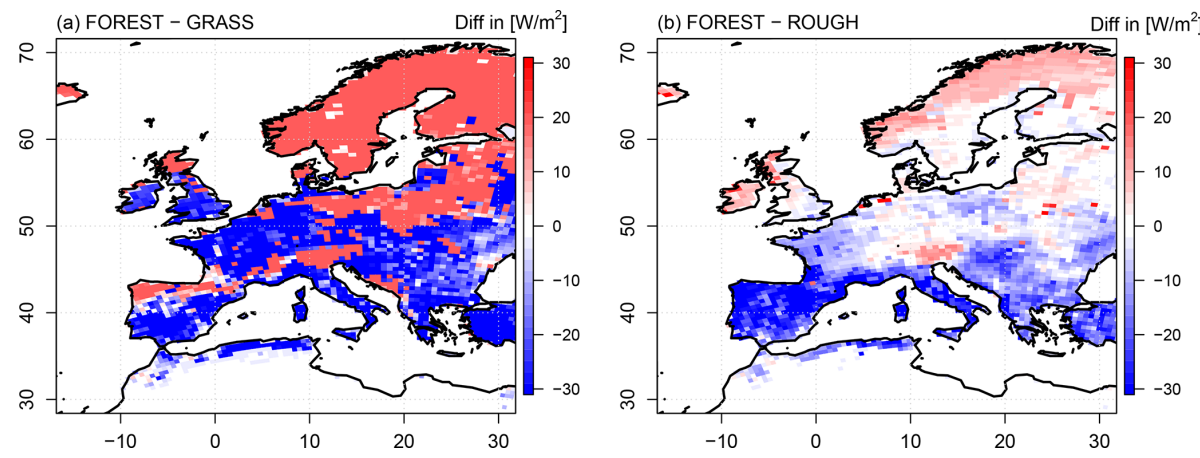

Figure 2. Differences in mean seasonal latent heat fluxes in summer between the FOREST and the GRASS experiments (a) and the FOREST and the ROUGH experiments (b) over the simulation period 1986-2015.

(Sect. 2) that changes in total evapotranspiration in summer are mainly associated with transpiration. At a depth of $15 \mathrm{~cm}$, almost all over Europe the soil is drier in the GRASS simulation (Fig. 3c) since grassland extracts water for transpiration mainly from this depth. The same applies to forest at $75 \mathrm{~cm}$ depth (Fig. 3d), but since forest is able, in contrast to grassland, to extract water from these deeper soil layers, the available soil water amount for transpiration in summer is higher in FOREST than in GRASS (Fig. 3a).

The ROUGH sensitivity simulation, with its reduced surface roughness, provides the opportunity to additionally investigate the impact of the resistance part $r_{\mathrm{a}}$ on the transpiration flux more precisely (Fig. 2b). In general, a reduced surface roughness reduces turbulent mixing, which is manifested in an increased $r_{\mathrm{a}}$. According to Eq. (2), this reduces the transfer coefficient $c$, and transpiration is impeded. This should consequently lead all over Europe to reduced transpiration rates in ROUGH, but this is only the case in northern Europe. In southern Europe and large parts of central Europe, evapotranspiration is even increased compared to FOREST. Thus, the ROUGH simulation exhibits astonishingly comparable evapotranspiration patterns to the GRASS run and does not behave anymore like a forest simulation. Since an increase in $r_{\mathrm{a}}$ should have an opposite effect, its impact on the transpiration flux signal must be negligible, at least in southern and central Europe, but the generally strong effects of the surface roughness change on evapotranspiration indicates that surface roughness is playing a major role in evapotranspiration beyond its impact on $r_{\mathrm{a}}$.

\subsection{Saturation deficit}

According to Eq. (1), the saturation deficit between the vegetation and the atmosphere is the driving force of transpiration which is regulated by the transfer coefficient $c$. In the FOREST simulation, this saturation deficit is reduced all over Europe compared to the GRASS simulation (Fig. 4a). Thus, all over Europe, the transpiration-facilitating vegetation characteristics of a forest are facing a reduced driving force of transpiration.

In southern Europe, the reduction in the saturation deficit is particularly pronounced. As a result, the reduced saturation deficit exceeds the impact of the increased transfer coefficient in the transpiration flux calculation (Eq. 1), and evapotranspiration is reduced. In northern Europe, on the contrary, the reduction in the saturation deficit in the FOREST simulation is less pronounced. As shown in Fig. 1, northern Europe is completely covered by coniferous forest in the FOREST simulation. Coniferous forest has a high LAI and low albedo values and thus low $r_{\mathrm{c}}$ and high $c$ values. In northern Europe, a slightly reduced saturation deficit consequently faces a high transfer coefficient. This higher transfer coefficient therefore exceeds the impact of the reduced saturation deficit in the flux calculation (Eq. 1), and evapotranspiration is increased. In central Europe, the saturation deficit in the FOREST run is comparable to northern Europe, but in contrast to northern Europe, regions of increased evapotranspiration are simulated, as well as regions of reduced evapotranspiration, compared to the GRASS simulation (Fig. 2a). As already mentioned in Sect. 3.1, the regions of increased evapotranspiration coincide with regions covered by conifer- 

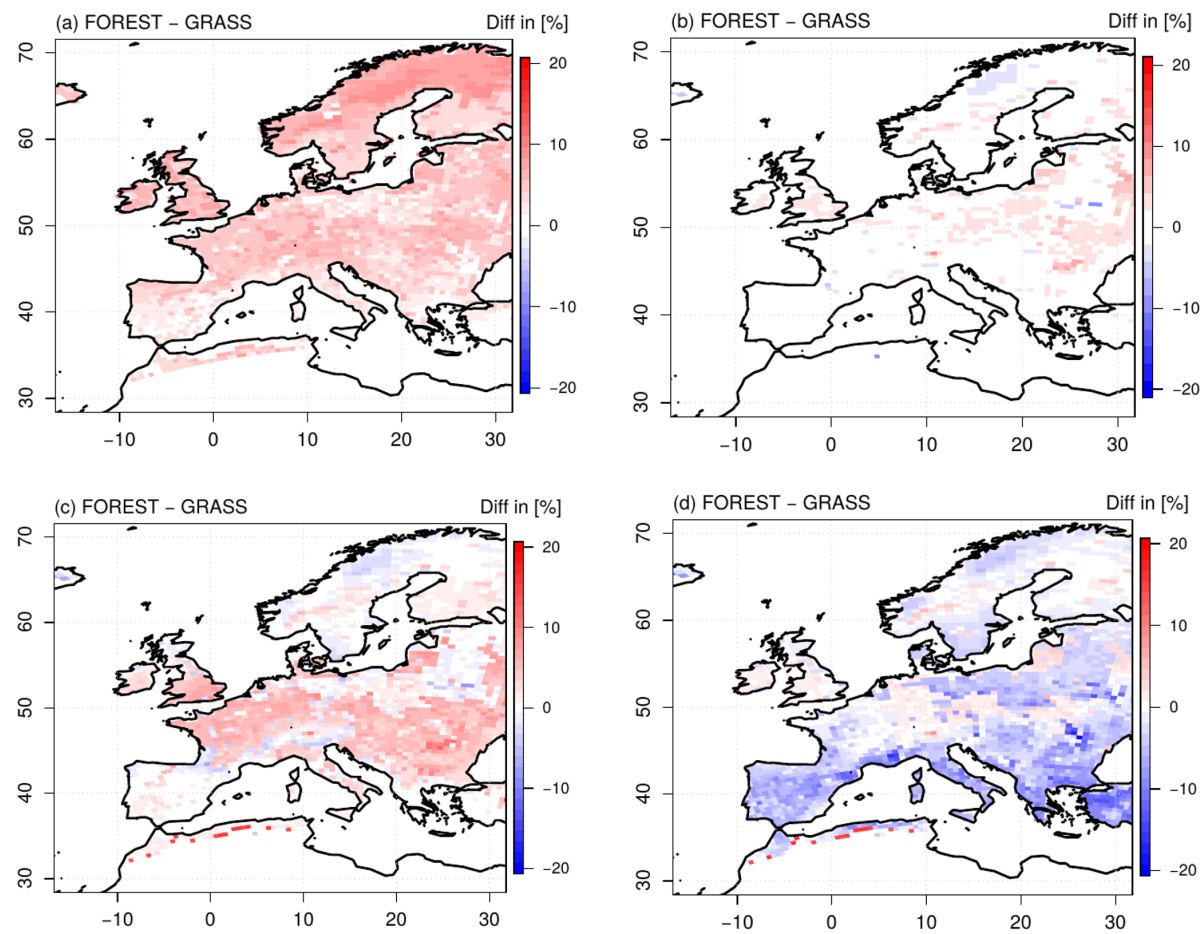

Figure 3. Differences between the FOREST and the GRASS experiments in summer for the available soil water amount for evapotranspiration (soil water content - residual soil water content) within the rooted soil column (a), in the upper soil layers (until $5 \mathrm{~cm}$ depth) (b), at a soil depth of $15 \mathrm{~cm}(\mathbf{c})$, at a soil depth of $75 \mathrm{~cm}(\mathbf{d})$ and over the simulation period 1986-2015.
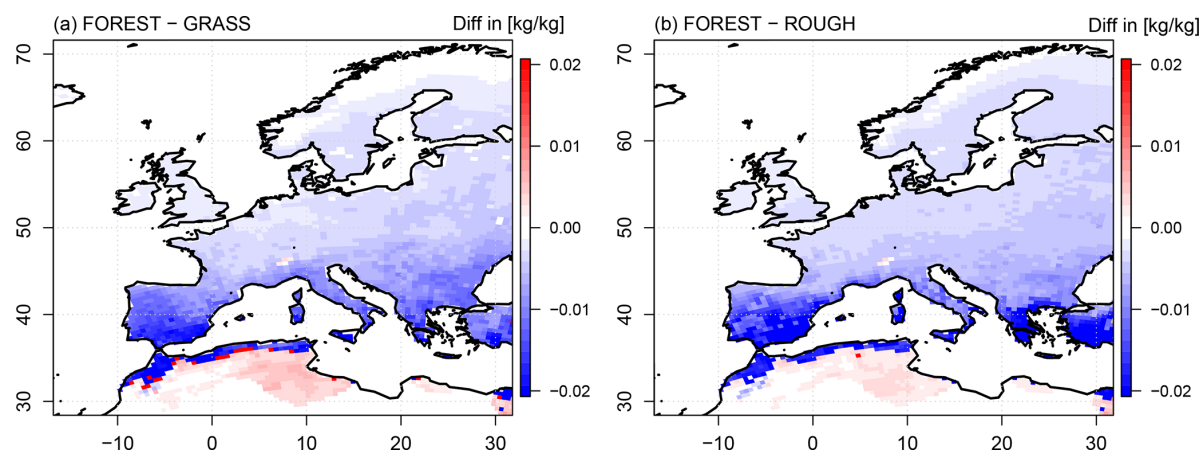

Figure 4. Differences in mean saturation deficit (in kilograms water vapor per kilogram wet air) between the vegetation and the atmosphere in summer between the FOREST and the GRASS experiments (a) and the FOREST and the ROUGH experiments (b) over the simulation period 1986-2015. The saturation deficit is calculated for the daily maximum surface temperature (top of vegetation).

ous forests, while regions of reduced evapotranspiration are covered by deciduous forests. Since the saturation deficit reduction in the FOREST run is comparable for both forest types in central Europe (Fig. 4a), these different evapotranspiration responses to afforestation must be associated with differences in the transfer coefficient $c$ (Eq. 1). The transfer coefficient $c$ of coniferous forest must therefore be higher than the one of deciduous forest. In a coniferous forest, LAI is increased, and albedo is reduced in comparison to a deciduous forest, while in a deciduous forest, the root depth and $c_{\mathrm{veg}}$ are increased. Thus, both forest types have characteris- tics which lead to high $c$ values. However, since evapotranspiration in central Europe is higher for coniferous forests than for deciduous forests, the impact of LAI and the albedo (pronounced in coniferous forests) on $c$ must be higher than the impact of the root depth and $c_{\mathrm{veg}}$ (pronounced in deciduous forests). As a result, the impact of the higher transfer coefficient $c$ of coniferous forests surpasses the effects of the lower saturation deficit in central Europe in the transpiration flux calculation, and evapotranspiration is increased, while for deciduous forests, the impact of the reduced saturation deficit is dominant, and evapotranspiration is reduced. 
As described in Sect. 3.1., surface roughness has only a minor impact on the extent of the transfer coefficient $c$, but its effects on the humidity gradients are large. As shown in Fig. 4b, the reduction in the surface roughness in the ROUGH simulation results in increased saturation deficits all over Europe which are similar to the GRASS run. Thus, the surface roughness is the main driver for the different saturation deficits in FOREST and GRASS. The reasons for this surface roughness effect on the saturation deficits are described in detail in the next section.

\subsection{Effects of surface roughness}

Differences in evapotranspiration as seen for the FOREST and GRASS runs (Fig. 2) inevitably affect the atmospheric conditions in these simulations. For instance, the increased evapotranspiration rates in northern Europe in FOREST lead to an increased cloud cover in this region (Fig. 5a). The incoming solar radiation is consequently reduced in comparison to GRASS. However, since the albedo of the trees in the FOREST simulation is lower than the albedo of grassland in the GRASS run, the reduction in the incoming solar radiation is compensated for, and net shortwave radiation is slightly increased in northern Europe (Fig. 5b). For the rest of the European continent, this albedo effect is even more strongly pronounced, and the net shortwave radiation is considerably increased since cloud cover is not changed compared to GRASS, but this increased radiative energy input does not result in higher surface temperatures (Fig. 6a; since evapotranspiration mainly takes place during the day, here and in the following, the daily maximum temperatures are considered). All over Europe, lower daily maximum surface temperatures are simulated in FOREST than in GRASS. These lower surface temperatures cannot be caused by an evaporative cooling associated with increased latent heat fluxes, as generally supposed (e.g., Bonan, 2008), since at least in southern and central Europe, evapotranspiration is reduced in FOREST (Fig. 2a). As stated by Breil et al. (2020), the lower surface temperatures in FOREST are mainly caused by increased sensible heat fluxes all over Europe (Fig. 6b) which transform and transport the increased energy input from the net shortwave radiation into the atmosphere without increasing the surface temperature.

These increased sensible heat fluxes are induced by the higher surface roughness of a forest compared to grassland, as demonstrated by the results of the ROUGH simulation (Figs. 5c-d and 6c-d). Due to the increased evapotranspiration rates in ROUGH in northern Europe (Fig. 2b), cloud cover is increased in this region in comparison to the FOREST run (Fig. 5c). The net shortwave radiation is consequently slightly reduced (Fig. 5d), but for the rest of the European continent, net shortwave radiation in FOREST and ROUGH is at the same high level due to the unchanged albedo values. The reduced surface roughness in ROUGH reduces the sensible heat transport into the atmosphere all over
Europe (Fig. 6d). Thus, the high radiative energy is not as efficiently transformed and transported into the atmosphere as in FOREST with the consequence that the surface temperatures are increased in a similar way to the GRASS simulation (Fig. 6c).

As described in Eq. (1), the saturation deficit between the surface and the atmosphere depends on the surface temperature. Due to the increased surface roughness of a forest, this surface temperature is reduced compared to grassland. As a result, the saturation deficit of forests to the atmosphere is lower than for grassland (Fig. 4a). Finally, this leads in southern and central Europe to a lower forest evapotranspiration (Fig. 2a). Thus, the lower surface temperatures of forests compared to grassland are there not as a result of evaporative cooling but of the increased surface roughness. These lower surface temperatures then, in turn, even decrease forest evapotranspiration.

\section{Discussion and conclusions}

In the framework of idealized regional climate simulations with CCLM-VEG3D for two extreme land use change scenarios (FOREST and GRASS), diverging evapotranspiration responses are simulated. In northern Europe, evapotranspiration is increased with afforestation; in southern and central Europe, evapotranspiration is decreased. Especially the reduced forest evapotranspiration rates in southern and central Europe are in contradiction to the prevailing scientific doctrine that forest evapotranspiration is enhanced (e.g., Bonan, 2008) due to deeper roots (Schenk and Jackson, 2003) and a higher leaf area index (Henderson-Sellers, 1993) than grassland. However, these results qualitatively reflect the varying evapotranspiration rates of forests and grasslands in $\mathrm{Eu}-$ ropean summer, documented in numerous observations and modeling studies (Zhang et al., 2001; Williams et al., 2012; Davin et al., 2020).

Climate simulations with incorporated land surface models (LSMs) are an appropriate method to analyze the reasons for these varying evapotranspiration rates of forests and grasslands. However, models constitute only a simplified description of reality and thus cannot represent the complex biogeophysical processes in nature comprehensively. For instance, VEG3D does not consider the effects of the multilayer canopy structure of trees (effects of shaded and unshaded leaves; Bonan et al., 2012) or the influence of the understory on evapotranspiration rates which can contribute substantially to total evapotranspiration in forests (e.g., Yepez et al., 2003). Furthermore, VEG3D does not consider the impact of temperature and vapor pressure deficit on stomata closure, but the results of model intercomparison studies show that more sophisticated LSMs in which these biogeophysical effects are integrated exhibit comparable evapotranspiration responses to afforestation as VEG3D (e.g., de Noblet-Ducoudré et al., 2012; Davin et al., 2020). 

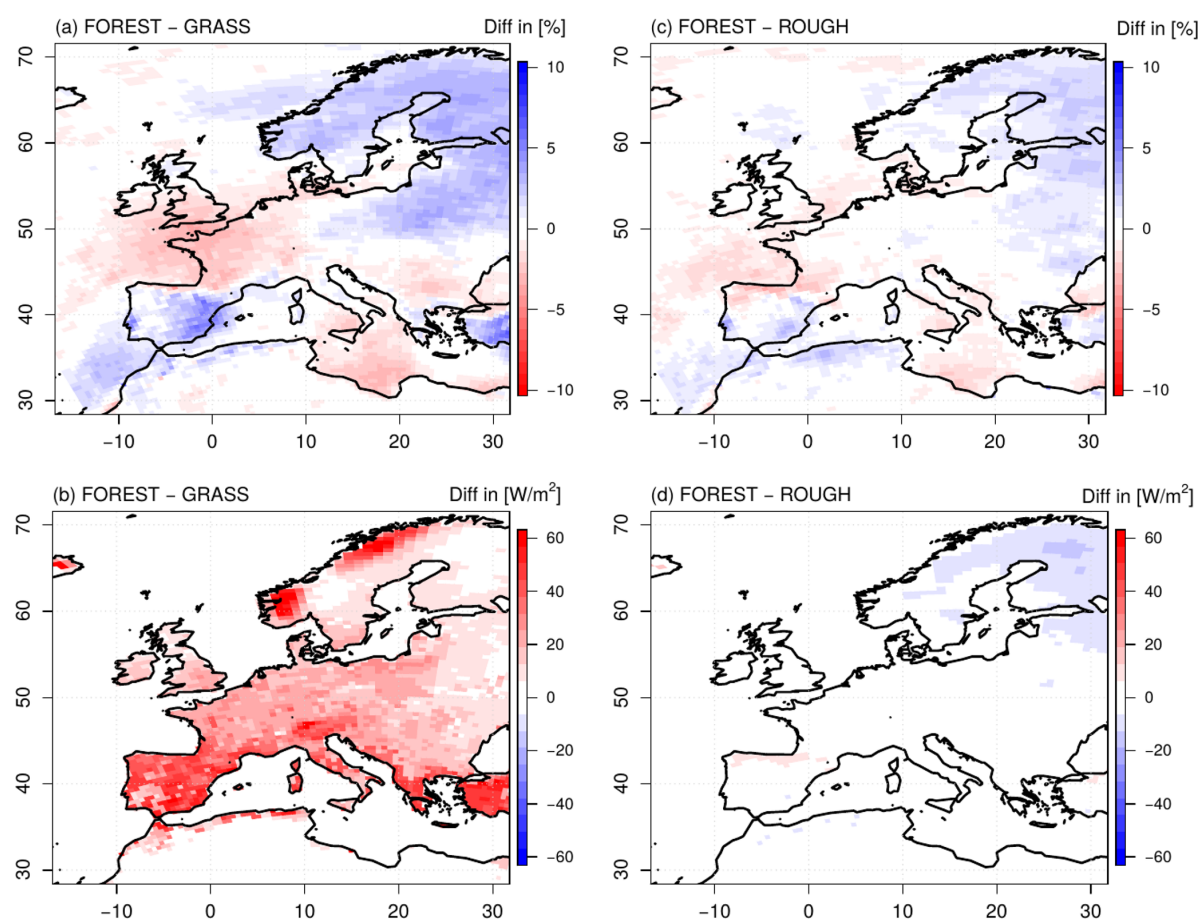

Figure 5. Differences in mean seasonal cloud cover $(\mathbf{a}, \mathbf{c})$ and net shortwave radiation $(\mathbf{b}, \mathbf{d})$ in summer between the FOREST and the GRASS experiments (a-b) and the FOREST and the ROUGH experiments (c-d) over the simulation period 1986-2015.


Figure 6. Differences in mean seasonal daily maximum surface (top of vegetation) temperature (a, c) and seasonal sensible heat fluxes $(\mathbf{b}, \mathbf{d})$ in summer between the FOREST and the GRASS experiments (a-b) and the FOREST and the ROUGH experiments (c-d) over the simulation period 1986-2015. 
For instance, in the framework of the LUCAS project, simulations with the classic model VEG3D and the more sophisticated Community Land Model under the same atmospheric boundary conditions show similar spatial patterns of increased or reduced evapotranspiration rates with afforestation (Davin et al., 2020). Thus, the differences in the model complexity (effects of shaded and unshaded leaves or the vapor pressure dependency of stomata closure) cannot be the main reason for the simulated differences in evapotranspiration responses in forests and grasslands. These different evapotranspiration responses must rather be caused by a fundamental mechanism, which is simulated in both classic and complex LSMs. In order to get to the bottom of these fundamental processes, the use of a less complex model can even be beneficial. In such a model, the degrees of freedom are reduced, and functional interrelations can consequently be deduced more easily. Therefore, by means of a sensitivity study with this less complex CCLM-VEG3D model in which the surface roughness of forests was reduced to grassland (ROUGH), this fundamental mechanisms behind the varying evapotranspiration rates of forests and grasslands could be clearly revealed:

Due to a higher surface roughness, the daily maximum surface temperatures (top of the vegetation) of a forest are lower than of grassland (Breil et al., 2020). The saturation deficit between the vegetation and the atmosphere (1) which depends on these surface temperatures (Eq. 1) is consequently reduced and counteracts the transpiration-facilitating characteristics of a forest (2), high transfer coefficient due to deep roots, high LAI and low albedo. Therefore, the question of whether forests or grasslands transpire more water depends on the balance between the two factors (1) and (2).

The simulation results show that the interplay of these two forces depends, on the one hand, on the latitude. In southern Europe with its intense solar radiation, the surface temperature strongly increases if energy is not efficiently transformed into sensible heat fluxes by turbulent processes. Due to its low surface roughness, grassland is not able to transform the solar energy as efficiently as forests. The surface temperature and thus also the saturation deficit (1) is consequently more strongly increased than for forest. The impact of factor (1) therefore exceeds the effects of factor (2), and grassland transpiration is increased compared to forest. In northern Europe, on the contrary, the incoming solar radiation is lower. Thus, the surface temperature differences and saturation deficits between forest and grassland (1) are not as pronounced as in the southern parts of Europe. The impact of factor (2) surpasses consequently the effects of factor (1), and forest transpiration is increased compared to grassland. The dependency of the evapotranspiration rates of forests and grasslands on the latitude is also documented in satellite observations (e.g., Li et al., 2015). In this context, the simulated increase in evapotranspiration with afforestation for large parts of central and northern Europe is in line with observations (e.g., Duveiller et al., 2018), while the sim- ulated reduction in evapotranspiration in the Mediterranean is not reflected by observations (e.g., Rohatyn et al., 2018). One potential explanation for these deviations between the CCLM-VEG3D model results and observations is the missing consideration of the summertime senescence of grasslands in Mediterranean regions and the associated reduction in grassland evapotranspiration (Ryu et al., 2008). Another possible reason for the disagreement between the simulation results and the observations is the missing consideration of vapor pressure effects on the stomatal resistance in CCLM-VEG3D. For instance, in southern Europe, the saturation deficit of forests is particularly lower than for grassland. In contrast to the simulated trees in CCLM-VEG3D, real trees are potentially able to adapt to this lower saturation deficit by further reducing the stomatal closure and thus the transfer coefficient. In line with the introduced evapotranspiration concept, the transpiration-facilitating characteristics of forests (2) would be further enhanced, counteracting the reduced saturation deficit (1) in southern Europe, and thus would increase forest evapotranspiration.

On the other hand, the simulation results show that the balance between factors (1) and (2) is differently pronounced for individual forest types. In central Europe, for instance, deciduous and coniferous forests show opposing evapotranspiration responses to afforestation, although they are facing a comparable saturation deficit (1). Differences in the evapotranspiration rates must consequently be associated with differences in the transfer coefficients (2). A deciduous forest, for instance, has a lower LAI and higher albedo values than a coniferous forest (Table 2). The transfer coefficient is consequently lower, and factor (2) is becoming weaker. The impact of the saturation deficit (1) is therefore dominating the effects of factor (2), and the transpiration rates of deciduous forests are reduced compared to grassland in central Europe, but for coniferous forest, which are facing a similar saturation deficit (1), the impact of factor (2) is increased due to the higher LAI and lower albedo values. The transpiration rates are consequently higher for coniferous forests in this region. These results are also in line with observation-based studies showing that evapotranspiration rates differ between different forest types (e.g., Brown et al., 2005), whereby higher evapotranspiration rates are generally assigned to coniferous forests (e.g., Teuling, 2018). Furthermore, Marc and Robinson (2007) showed that also the age of the forest affects evapotranspiration.

In this study, only the results of model simulations are presented which obviously depend on the used parameterizations and parameters. In the specific CCLM-VEG3D setup, for instance, only two different forest types (coniferous and deciduous) are applied, which might not completely represent the whole variety of European forests. Generalizations, as well as under- or overestimations of certain physical processes, can result locally. Therefore, this study does not claim for general validity. The transpiration rates of forests and grasslands depend on the weighting of the respective factors 
(1) and (2). Since this weighting is model-specific, slightly different evapotranspiration responses in forests and grasslands are anticipated for different model simulations. Moreover, different evapotranspiration responses can also be expected within observational data since the biogeophysical characteristics of forests and grasslands vary also in nature (Garratt, 1993; Henderson-Sellers, 1993; Schenk and Jackson, 2003). Taking these uncertainties into account, differences between the CCLM-VEG3D results and observations, as present in southern Europe (Rohatyn et al., 2018), can potentially be explained.

However, it is generally difficult to assess the effects of afforestation by a direct comparison of the CCLM-VEG3D model results with observational data due to discrepancies on the scale of processes considered in models and observations (Davin et al., 2020). In observational data (satellite data, as well as data from eddy covariance flux towers), forests and grasslands in immediate vicinity are compared. Differences in the measured fluxes are therefore directly related to the local land cover differences (Bright et al., 2017). In contrast, differences in model results for forests and grasslands are additionally affected by large-scale atmospheric feedback processes (Winckler et al., 2017). Therefore, it is difficult to assess the CCLM-VEG3D model results quantitatively and qualitatively in comparison to observations. Thus, with this study, the question of whether in specific regions observation-based studies are correct which show higher evapotranspiration rates of forests (e.g., Zhang et al., 2001; Li et al., 2015; Chen et al., 2018; Duveiller et al., 2018) or studies which document the opposite behavior is not intended to be answered (e.g., Wicke and Bernhofer, 1996; Teuling et al., 2010; Williams et al., 2012). In this study, a mechanism is rather presented that explains how these different transpiration responses in forests and grasslands can generally evolve in Europe and by which factors they are controlled. In this context, especially an explanation for the hardly comprehensibly lower evapotranspiration rates of forests during summer can be provided in a physically consistent way.

Code availability. The coupled version of COSMO-CLM and VEG3D is available upon request from Marcus Breil.

Data availability. CCLM-VEG3D data presented in the paper can be accessed by contacting Marcus Breil. The data will be archived at the DKRZ (German Climate Computing Centre). ERA-Interim boundary conditions can be obtained at https://apps.ecmwf.int/ datasets/data/interim-full-daily/ (ECMWF, 2021).

Author contributions. MB designed the study and performed the model simulations and analysis. All authors (MB, ELD and DR) contributed to writing and revising the paper.
Competing interests. The authors declare that they have no conflict of interest.

Acknowledgements. LUCAS is supported by WCRP CORDEX as a Flagship Pilot Study. Marcus Breil acknowledges funding from the Federal Ministry of Education and Research in Germany (BMBF) under the ClimXtreme research program. Edouard L. Davin acknowledges support from the Swiss National Science Foundation (SNSF) through the CLIMPULSE project. All simulations were performed at the German Climate Computing Center (DKRZ). Marcus Breil acknowledges support from the KIT Publication Fund of the Karlsruhe Institute of Technology.

Financial support. The article processing charges for this openaccess publication were covered by a Research Centre of the Helmholtz Association.

Review statement. This paper was edited by Christopher Still and reviewed by two anonymous referees.

\section{References}

Bonan, G. B.: Forests and climate change: forcings, feedbacks, and the climate benefits of forests, Science, 320, 1444-1449, 2008.

Bonan, G. B., Oleson, K. W., Fisher, R. A., Lasslop, G., and Reichstein, M.: Reconciling leaf physiological traits and canopy flux data: Use of the TRY and FLUXNET databases in the Community Land Model version 4, J. Geophys. Res.-Biogeosci., 117, 2012.

Breil, M. and Schädler, G.: Quantification of the uncertainties in soil and vegetation parameterizations for regional climate simulations in Europe, J. Hydrometeorol., 18, 1535-1548, 2017.

Breil, M., Rechid, D., Davin, E. L., de Noblet-Ducoudré, N., Katragkou, E., Cardoso, R. M., Hoffmann, P., Jach, L. L., Soares, P. M. M., Sofiadis, G., Strada, S., Strandberg, G., Tölle, M. H., and Warrach-Sagi, K.: The Opposing Effects of Reforestation and Afforestation on the Diurnal Temperature Cycle at the Surface and in the Lowest Atmospheric Model Level in the European Summer, J. Climate, 33, 9159-9179, 2020.

Bright, R. M., Davin, E., O’Halloran, T., Pongratz, J., Zhao, K., and Cescatti, A.: Local temperature response to land cover and management change driven by non-radiative processes, Nat. Clim. Change, 7, 296-302, 2017.

Brown, A. E., Zhang, L., McMahon, T. A., Western, A. W., and Vertessy, R. A.: A review of paired catchment studies for determining changes in water yield resulting from alterations in vegetation, J. Hydrol., 310, 28-61, 2005.

Businger, J. A., Wyngaard, J. C., Izumi, Y., and Bradley, E. F.: FluxProfile Relationships in the Atmospheric Surface Layer, J. Atmos. Sci., 28, 181-189, 1971.

Chen, L., Dirmeyer, P. A., Guo, Z., and Schultz, N. M.: Pairing FLUXNET sites to validate model representations of landuse/land-cover change, Hydrol. Earth Syst. Sci., 22, 111-125, https://doi.org/10.5194/hess-22-111-2018, 2018. 
Davin, E. L., Rechid, D., Breil, M., Cardoso, R. M., Coppola, E., Hoffmann, P., Jach, L. L., Katragkou, E., de Noblet-Ducoudré, N., Radtke, K., Raffa, M., Soares, P. M. M., Sofiadis, G., Strada, S., Strandberg, G., Tölle, M. H., Warrach-Sagi, K., and Wulfmeyer, V.: Biogeophysical impacts of forestation in Europe: first results from the LUCAS (Land Use and Climate Across Scales) regional climate model intercomparison, Earth Syst. Dynam., 11, 183-200, https://doi.org/10.5194/esd-11-1832020, 2020.

Deardorff, J. W.: Efficient prediction of ground surface temperature and moisture, with inclusion of a layer of vegetation, J. Geophys. Res.-Oceans, 83, 1889-1903, 1978.

Dee, D. P., Uppala, S. M., Simmons, A. J., Berrisford, P., Poli, P., Kobayashi, S., Andrae, U., Balmaseda, M. A., Balsamo, G., Bauer, P., Bechtold, P., Beljaars, A. C. M., van de Berg, L., Bidlot, J., Bormann, N., Delsol, C., Dragani, R., Fuentes, M., Geer, A. J., Haimberger, L., Healy, S. B., Hersbach, H., Holm, E. V., Isaksen, L., Kallberg, P., Köhler, M., Matricardi, M., McNally, A. P., Monge-Sanz, B. M., Morcrette, J.-J., Park, B.-K., Peubey, C., de Rosnay P., Tavolato, C., Thepaut, J.-N., and Vitart, F.: The ERA-Interim reanalysis: Configuration and performance of the data assimilation system, Q. J. R. Meteorol. Soc., 137, 553-597, 2011.

de Noblet-Ducoudré, Boissier, J.-P., Pitman, A., Bonan, G. B., Brovkin, V., Cruz, F., Delire, C., Gayler, V., van den Hurk, B., Lawrence, P. J., van der Mollen, M. K., Müller, C., Reick, C. H., Strengers, B. J., and Voldoire, A.: Determining robust impacts of land-use-induced land cover changes on surface climate over North America and Eurasia: results from the first set of LUCID experiments, J. Climate, 25, 3261-3281, 2012.

ECMWF: ERA Interim, Daily, available at: https://apps.ecmwf.int/ datasets/data/interim-full-daily/, last access: 22 February 2021.

Duveiller, G., Hooker, J., and Cescatti, A.: The mark of vegetation change on Earth's surface energy balance, Nat. Commun., 9, 112, 2018.

Garratt, J. R.: Sensitivity of climate simulations to land-surface and atmospheric boundary-layer treatments-a review, J. Climate, 6, 419-448, 1993.

Goudriaan, J.: Crop micrometeorology: a simulation study (Doctoral dissertation, Pudoc), Wageningen, 1977.

Harper, A. B., Powell, T., Cox, P. M., House, J., Huntingford, C., Lenton, T. M., Sitch, S., Burke, E., Chadburn, S. E., Collins, W. J., Comyn-Platt, E., Daioglou, V., Doelman, J. C., Hayman, G., Robertson, E., van Vuuren, D., Wiltshire, A., Webber, C. P., Bastos, A., Boysen, L., Ciais, P., Devaraju, N., Jain, A. K., Krause, A., Poulter, B., and Shu, S.: Land-use emissions play a critical role in land-based mitigation for Paris climate targets, Nat. Commun., 9, 2938, https://doi.org/10.1038/s41467-018-05340z, 2018.

Henderson-Sellers, A.: A factorial assessment of the sensitivity of the BATS land-surface parameterization scheme, J. Climate, 6, 227-247, 1993.

Intergovernmental Panel on Climate Change: Climate change and land: an IPCC special report on climate change, desertification, land degradation, sustainable land management, food security, and greenhouse gas fluxes in terrestrial ecosystems, available at: https://www.ipcc.ch/report/srccl/ (last access: 22 February 2021), 2019.
Jacob, D., Petersen, J., Eggert, B., Alias, A., Christensen, O. B., Bouwer, L. M., Braun, A., Colette, A., Deque, M., Georgievski, G., Georgopoulou, E., Gobiet, A., Menut, L., Nikulin, G., Haensler, A., Hempelmann, N., Jones, C., Keuler, K., Kovats, S., Kröner, N, Kotlarski, S., Kriegsmann, A., Martin, E., van Meijgaard, E., Moseley, C., Pfeifer, S., Preuschmann, S., Radermacher, C., Radtke, K., Rechid, D., Rounsevell, M., Samuelsson, P., Somot, S., Soussana, J.-F., Teichmann, C., Valentini, R., Vautard, R., Weber, B., and Yiou, P.: EURO-CORDEX: new highresolution climate change projections for European impact research, Reg. Environ. Change, 14, 563-578, 2014.

Lejeune, Q., Seneviratne, S. I., and Davin, E. L.: Historical landcover change impacts on climate: comparative assessment of LUCID and CMIP5 multimodel experiments, J. Climate, 30, 14391459, 2017.

Leuzinger, S., Zotz, G., Asshoff, R., and Körner, C.: Responses of deciduous forest trees to severe drought in Central Europe, Tree Physiol., 25, 641-650, 2005.

Li, Y., Zhao, M., Motesharrei, S., Mu, Q., Kalnay, E., and Li, S.: Local cooling and warming effects of forests based on satellite observations, Nat. Commun., 6, 1-8, 2015.

Marc, V. and Robinson, M.: The long-term water balance (19722004) of upland forestry and grassland at Plynlimon, mid-Wales, Hydrol. Earth Syst. Sci., 11, 44-60, https://doi.org/10.5194/hess11-44-2007, 2007.

Meier, R., Davin, E. L., Lejeune, Q., Hauser, M., Li, Y., Martens, B., Schultz, N. M., Sterling, S., and Thiery, W.: Evaluating and improving the Community Land Model's sensitivity to land cover, Biogeosciences, 15, 4731-4757, https://doi.org/10.5194/bg-154731-2018, 2018.

Monin, A. and Obukhov, A.: Basic laws of turbulent mixing in the surface layer of the atmosphere, Contrib. Geophys. Inst. Acad. Sci, USSR, 151, 163-187, 1954.

Niu, G. Y., Yang, Z.-L., Mitchell, K. E., Chen, F., Ek, M. B., Barlage, M., Kumar, A., Manning, K., Niyogi, D., Rosero, E., Tewari, M., and Xia, Y.: The community Noah land surface model with multiparameterization options (Noah-MP): 1. Model description and evaluation with localscale measurements, J. Geophys. Res.-Atmos., 116, D12109, https://doi.org/10.1029/2010JD015139, 2011.

Oleson, K. W., Lawrence, D. M., Bonan, G. B., Drewniak, B., Huang, M., Koven, C. D., Levis, S., Li, F., Riley, W. J., Subin, Z. M., Swenson, S. C., and Thornton, P. E.: Technical description of version 4.5 of the Community Land Model (CLM), Boulder, CO, 420 pp., 2013.

Rechid, D., E. Davin, N. de Noblet-Ducoudré, and E. Katragkou: CORDEX Flagship Pilot Study LUCAS - Land Use \& Climate Across Scales - a new initiative on coordinated regional land use change and climate experiments for Europe, EGU General Assembly 2017, Vienna, Austria, 23-28 April 2017, 13172, 2017.

Rockel, B., A. Will, and A. Hense: The regional climate model COSMO-CLM (CCLM), Meteorol. Z., 17, 347-348, 2008.

Roe, S., Streck, C., Obersteiner, M., Frank, S., Griscom, B., Drouet, L., Fricko, O., Gusti, M., Harris, N., Hasegawa, T., Hausfather, Z., Havlík, P., House, J., Nabuurs, G.-J., Popp, A., Sanz Sánchez, M. J., Sanderman, J., Smith, P., Stehfest, E., and Lawrence, D.: Contribution of the land sector to a $1.5^{\circ} \mathrm{C}$ world, Nat. Clim. Change, 1-12, 2019. 
Rohatyn, S., Rotenberg, E., Ramati, E., Tatarinov, F., Tas, E., and Yakir, D.: Differential impacts of land use and precipitation on “ecosystem water yield", Water Resour. Res., 54, 5457-5470, 2018.

Ryu, Y., Baldocchi, D. D., Ma, S., and Hehn, T.: Interannual variability of evapotranspiration and energy exchange over an annual grassland in California, J. Geophys. Res.-Atmos., 113, D09104, https://doi.org/10.1029/2007JD009263, 2008.

Schenk, H. J. and Jackson, R. B.: Global distribution of root profiles in terrestrial ecosystems, Data set, Oak Ridge National Laboratory Distributed Active Archive Center, Oak Ridge, TN, USA), 2003. https://doi.org/10.3334/ORNLDAAC/660, 2003.

Sonntag, S., Pongratz, J., Reick, C. H., and Schmidt, H.: Reforestation in a high- $\mathrm{CO}_{2}$ world-Higher mitigation potential than expected, lower adaptation potential than hoped for, Geophys. Res. Lett., 43, 6546-6553, 2016.

Taconet, O., Bernard, R., and Vidal-Madjar, D.: Evapotranspiration over an agricultural region using a surface flux/temperature model based on NOAA-AVHRR data, J. Clim. Appl. Meteorol., 25, 284-307, 1986.

Teuling, A. J.: A forest evapotranspiration paradox investigated using lysimeter data, Vadose Zone J., 17, 1-7, https://doi.org/10.2136/vzj2017.01.0031, 2018.

Teuling, A. J., Seneviratne, S. I., Stöckli, R., Reichstein, M., Moors, E., Ciais, P., Luyssaert, S., van den Hurk, B., Ammann, C., Bernhofer, C., Dellwik, E., Gianelle, D., Gielen, B., Grünwald, T., Klumpp, K., Montagnani, L., Moureaux, C., Sottocornola, M., and Wohlfahrt, G.: Contrasting response of European forest and grassland energy exchange to heatwaves, Nat. Geosci., 3, 722$727,2010$.
Von Randow, C., Manzi, A. O., Kruijt, B., de Oliveira, P. J., Zanchi, F. B., Silva, R. L., Hodnett, M. G., Gash, J. H. C., Elbers, J. A., Waterloo, M. J., Cardoso, F. L., and Kabat, P.: Comparative measurements and seasonal variations in energy and carbon exchange over forest and pasture in South West Amazonia, Theor. Appl. Climatol., 8, 5-26, 2004.

Wicke, W. and Bernhofer, C.: Energy balance comparison of the Hartheim forest and an adjacent grassland site during the HartX experiment. Theor. Appl. Climatol., 53, 49-58, 1996.

Williams, D., Reichstein, M., Buchmann, N., Baldocchi, D., Beer, C., Schwalm, C., Wohlfahrt, G., Hasler, N., Bernhofer, C., Foken, T., Papale, D., Schymanski, T., and Schaefer, K.: Climate and vegetation controls on the surface water balance: Synthesis of evapotranspiration measured across a global network of flux towers, Water Resour. Res., 48, W06523, https://doi.org/10.1029/2011WR011586, 2012.

Winckler, J., Reick, C. H., and Pongratz, J.: Robust identification of local biogeophysical effects of land-cover change in a global climate model, J. Climate, 30, 1159-1176, 2017.

Yepez, E. A., Williams, D. G., Scott, R. L., and Lin, G.: Partitioning overstory and understory evapotranspiration in a semiarid savanna woodland from the isotopic composition of water vapor, Agr. Forest Meteorol., 119, 53-68, 2003.

Zhang, L., Dawes, W. R., and Walker, G. R.: Response of mean annual evapotranspiration to vegetation changes at catchment scale, Water Resour. Res., 37, 701-708, 2001. 